\title{
Investigation of to the Effect of Bedrock Stiffness on Seismic Behaviour of Roller Compacted Concrete Dam
}

\author{
Mohammad Jalali a , Majid Pasbani Khiavi ${ }^{b^{*}}$, Mortaza Ali Ghorbani ${ }^{\mathrm{c}}$ \\ ${ }^{a}$ M. Sc. student, Faculty of Engineering, University of Mohaghegh Ardabili, Ardabil, Iran. \\ ${ }^{b}$ Associate professor (Ph.D.), Faculty of Engineering, University of Mohaghegh Ardabili, Ardabil, Iran. \\ ${ }^{c}$ Assistant professor, Faculty of Engineering, University of Mohaghegh Ardabili, Ardabil, Iran.
}

Received 21 July 2017; Accepted 30 August 2017

\begin{abstract}
In this research, the effect of bedrock stiffness on seismic performance of roller compacted concrete (RCC) dam is evaluated using probabilistic analysis. Due to the geometry and behavior of RCC dams, a two-dimensional modeling was selected for system. Ansys software is used for modeling and analysis of dam-reservoir- foundation system. Newmark implicit time integration scheme is developed to solve the time-discretized equations which are an unconditionally stable method. The Watana dam, due to San Fernando earthquake has been selected as a case study. In order to propagate the parametric sensitivity to the seismic performance of the system, Monte Carlo simulation with Latin hypercube sampling (LHS) method is used as a probabilistic method and uncertainty analysis. The sensitivity of responses under seismic loading is reliably examined utilizing different values of ratio of bedrock stiffness to body concrete stiffness as random inputs. Consider to obtained results, it is revealed that the bedrock stiffness how can effect on seismic behavior of concrete gravity dams due to earthquake. Regarding the safety of dams due to compressive stresses, various ways have been assessed to investigate the induced tensile stress in the heel and the results have been investigated. Finally, appropriate range of the ratio of bedrock stiffness to concrete stiffness of dam body is presented to assess the safety design.
\end{abstract}

Keywords: Uncertainty; RCC Dam; Bedrock Stiffness; Latin Hypercube Sampling; Interaction.

\section{Introduction}

In last decades, the use of roller compacted concrete (RCC) dam made a revolution in dam industry. Some purposes such as the high speed of construction and also the economical design were led such structures to be regarded by engineers using RCC technology. So, it is necessary to propose a proper method to design and analyze these kinds of dams with respecting to some factors. These factors can be the construction location and design on the basis of appropriate stiffness of foundation or bedrock.

Chuhan and et al. studied the nonlinear failure of roller compacted concrete dams using laboratory tests. In their research, samples of roller compacted concrete used in construction of Longtan dam was tested and the required nonlinear parameters and stress-strain curve in tension were obtained to use in nonlinear analysis. The biggest block of dam with nonlinear failure criterion undertook the nonlinear seismic analysis. Obtained results illustrated cracks near to dam heel and at the parts of inclination in downstream spread to the upstream [1].

Hui Zou and Trevor offered a numerical model for simulation of behavior of roller compacted concrete dams in which the stress-strain relation have been modeled with multi-layer structure to define elastic and elastic-plastic behavior. As

\footnotetext{
* Corresponding author: pasbani@uma.ac.ir

$>$ This is an open access article under the CC-BY license (https://creativecommons.org/licenses/by/4.0/).

(C) Authors retain all copyrights.
} 
an operational sample, the finite element model of Longtan dam with four various mixture designs of roller compacted concrete applying different strength properties were used for disparate parts of body [2].

To consider the uncertainty, one of the methods for structure analysis is design based on probabilities with considering a variable range for effective parameters. One of the important aspects based on engineering performance of earthquake is the accurate estimation of seismic response and structure capacity [3]. There are two important sources of uncertainty in seismic performance of structure: a) phenomenon of randomness, b) physical uncertainty due to modelling hypothesis, omissions or existing errors [4]. Adequate perception about structure expected responses can be effective on the probabilistic analysis with respect to the uncertainty [5]. Calculation of various types of seismic performance of structures regarding the physical uncertainty usually is carried out by the use of safety factors or standard dispersion criterion [6]. With respect to both of sources of uncertainty in structural engineering, a very strong method is doing probabilistic analysis by use of Monte Carlo simulation [7]. Several researches have been conducted to restrict the necessary options and gaining a proper method for seismic performance of model $[8,9]$. But, it has been attempted partly for concrete dams. The seismic response of concrete dams which are among the great infrastructures can be examined under the effect of various uncertainties [10]. Many researches such as Altarejos-Garcia et al. have been concentrated on the validity of this analysis on the dams under hydraulic loading which have estimated the failure probability of concrete gravity dam by considering sliding failure under hydraulic loading [11]. Carvajal et al. proposed a probabilistic method to evaluate hydraulic loads and shear strength of roller compacted concrete in gravity dams [12].

In recent studies about the application of probabilistic analysis, Alembagheri and Seyedkazemi investigated the seismic behavior of concrete gravity dam by considering the parameter of concrete tensile behavior as sensitivity parameter. The results illustrated that the accurate examination of tensile behavior and ultimate failure of concrete in gravity dams requires a suitable definition of nonlinear model of materials for tensile behavior of concrete [13].

Using of Monte-Carlo simulation and sensitivity analysis Pasbani Khiavi have investigated the effect of bed absorption coefficient in seismic performance of concrete dam. Obtained results represent clearly the capability of probabilistic analysis in the estimation of seismic response of concrete dam to bed absorption effects [14].Lupoi and Callari derived the fragility curves based on an innovative procedure where the randomness of external actions is treated separately from the structural uncertainty using linear analysis [15]. Ghanaat and et al. developed a set of fragility curves for different concrete dams accounting for the material modelling and seismic uncertainties. The impact of different failure modes were also considered on fragility functions [16, 17].

Pasbani Khiavi investigated the effect of the modulus of elasticity of concrete on seismic behavior of Koyna gravity dam in India using probabilistic analysis. The results show that the modulus of elasticity significantly how can effects on seismic behaviour of concrete gravity dams [18]. Aliberti and et al. studied on the seismic performance of the San Pietro dam located in Southern Italy, with different levels of accuracy, through pseudo-static with simplifieddisplacement and dynamic 2D finite difference analyses. The results of the analyses show a satisfactory behavior of the dam for the selected input motions [19]. Ansari and Agarwal investigated effects of re-entrant corner in the geometric configurations of high concrete gravity dams on seismic behaviour using incremental dynamic analysis. Crack patterns were obtained for the typical geometric configurations used in the high concrete gravity dams. In their study, the performance of the dam models are compared for before and after modifications incorporated in their geometric configurations using crack profile, IDA curves and fragility curves [20].

Regarding to the high importance of roller compacted concrete dam design and also the existence of uncertainty in estimation of some parameters such as bedrock stiffness, the aim of present study is to investigate the effect of the relation between the stiffness of foundation and dam body in seismic representation of these types of dams using probabilistic analysis and Monte-Carlo method. This method demonstrates very well the effect of various factors which are influential in designing and structural analysis. For this purpose in this research, to assess the evaluation of uncertainty due to the effect of bedrock stiffness, a coefficient named $W$ has been defined which shows the relation between the stiffness of foundation and dam body. $W$ has been selected as the input variable and the maximum displacement of dam crest, $1^{\text {st }}$ and $3^{\text {rd }}$ principle stresses have been considered as critical output parameters in probabilistic analysis. The effect of $W$ has been investigated on output parameters.

\subsection{Applied Conditions on System}

According to the governing conditions on the structure from hydrodynamic point of view, the model is considered with respect to the following assumptions:

- The model is considered two dimensional because of the behavior of roller compacted concrete dam and the geometric shape of reservoir.

- The main purpose of this research is to investigate the effect of bedrock stiffness consider to body stiffness on seismic performance of RCC dams. Therefore the dam materials are assumed elastic solid with linear behaviour. 
- For reservoir model, the governing equation is Navier-Stokes in which the fluid is supposed as non-rotating, non-viscous, with linear compressibility and small displacements. Moreover, the effects of gravity waves in free surface are ignored and at free surface, pressure is equal to zero.

- The analysis is carried out in time domain and Newmark method is used to solve dynamic equation.

- For different parts of dam, plane stress model and for foundation, the plane strain and mass less model is considered.

\subsection{Modelling of Dam Structure}

The equation which defines the dam behavior is equation of motion. To apply the interaction effect between fluid and structure, the hydrodynamic load must be added at the interface of dam and reservoir.

$$
K u(t)+C \dot{u}(t)+M \ddot{u}(t)=F^{e}(t)+F^{P r}
$$

In which, $M$ is mass matrix, $C$ damping matrix and $K$ is the stiffness matrix of structure. $u$ is the relative displacement vector, $\dot{u}$ is the relative speed vector and $\ddot{u}$ is the relative acceleration vector. $F^{e}(t)$ is the vector of earthquake force applied on structure and $F^{P r}$ is the pressure load applied from reservoir on dam in interface because of interaction.

\subsection{Modeling of Reservoir}

In problems relevant to acoustic interaction of structure and fluid, the equation related to structural dynamic can be considered using Navier-Stokes equation, momentum and continuity equations of fluid. With the assumption that the water within the reservoir is non-viscous, compressible and with small displacements, continuity equation and momentum will be summarized into wave equation. Also, the pressure exerted from water on dam in interface place is considered for formation of interaction matrix.

$$
\frac{\partial^{2} P_{x}}{\partial x^{2}}+\frac{\partial^{2} P_{y}}{\partial y^{2}}=\frac{1}{c^{2}} \frac{\partial^{2} P}{\partial t^{2}}
$$

In which, $c=\sqrt{k / \rho_{0}}$ is the speed of acoustic waves in water, $\rho_{0}$ is the mass density of fluid, $k$ is bulk modulus, $P$ is hydrodynamic pressure and $t$ is time.

\subsection{Applied Boundary Conditions}

On free surface of reservoir, the effects of surface waves have been neglected and pressure is supposed as zero on the reservoir water level. It means:

$$
P=0
$$

The boundary term of interaction in dam-reservoir and foundation-reservoir interface will be exerted as below:

$$
\frac{\partial P}{\partial n}=-\rho_{0} \vec{a}_{n s}
$$

In which $n$ denotes the inward normal direction to a boundary, $a_{n s}$ the normal component of boundary acceleration and $\rho_{0}$ the mass density of water.

At the far end of reservoir, Sommerfeld boundary condition is used as following:

$$
\frac{\partial P}{\partial x}=-\frac{1}{c} \frac{\partial P}{\partial t}
$$

\subsection{Finite Element Formulation}

The governing equations of dam-reservoir-foundation system have been expanded in matrix form by use of finite element method. Discretized dynamic equation of dam system can be formulized by using structural elements. In order to apply the effects of interaction, it is necessary to add the compressive load applied from fluid on the structure to formulation. The matrixes of reservoir elements will be extracted by discretization of wave equation. In extraction of matrixes, velocities and accelerations will be developed in the form of the first and second derivatives [21]. Discretized equations have been solved simultaneously or by using the repetitive method of try and error and then the results are elicited for system. In addition, for dynamic analysis and calculations, the Newmark method, which is unconditionally stable, has been used. 


\subsection{Model Analysis}

As a case study, two-dimensional model of Watana dam in Alaska has been selected. The geometric properties of case model with reservoir and foundation have been depicted in Figure 1. in which all dimensions are in meter. Modulus of elasticity, weight per unit volume, Poisson's coefficient of concrete are respectively $25 \mathrm{GPa}, 2500 \mathrm{~kg} / \mathrm{m}^{3}$ and 0.25 and also, the modulus of elasticity of foundation is $37 \mathrm{GPa}$ and its Poisson's coefficient is 0.30 .

The velocity of compressive waves in water is $1440 \mathrm{~m} / \mathrm{s}$ and its density has been assumed as $1000 \mathrm{~kg} / \mathrm{m}^{3}$. For finite element model, the length of reservoir has been considered three times as the height of dam and the height of foundation is one time as the height of dam. For truncated boundary of reservoir, Sommerfeld boundary condition has been used and the time step has been chosen as $\Delta t=0.01 \mathrm{sec}$.

In dynamic analysis of structure and foundation, damping property has a significance importance. $\mathrm{T}$ consider damping in time history analysis Rayleigh damping is used as following relation:

$$
[C]=\alpha[M]+\beta[K]
$$

In which $[M],[C]$ and $[K]$ are mass, damping and stiffness matrices respectively and $\alpha$ and $\beta$ are Rayleigh coefficients. After modal analysis of model and obtaining the first and second frequency of system, $\alpha=0.43$ and $\beta=0.0057$ has been calculated respectively. Ansys software based on finite element method has been used for modeling and analysis. To achieve enough accuracy with less computing effort, 6531 nodes have been used in finite element model of damreservoir- foundation system. For discretization of dam and foundation model, the PLANE183 element and for water, the FIUID29 element has been used which show the compressibility property of fluid [22]. Finite elements discretization of the considered model has been shown in Figure 1.

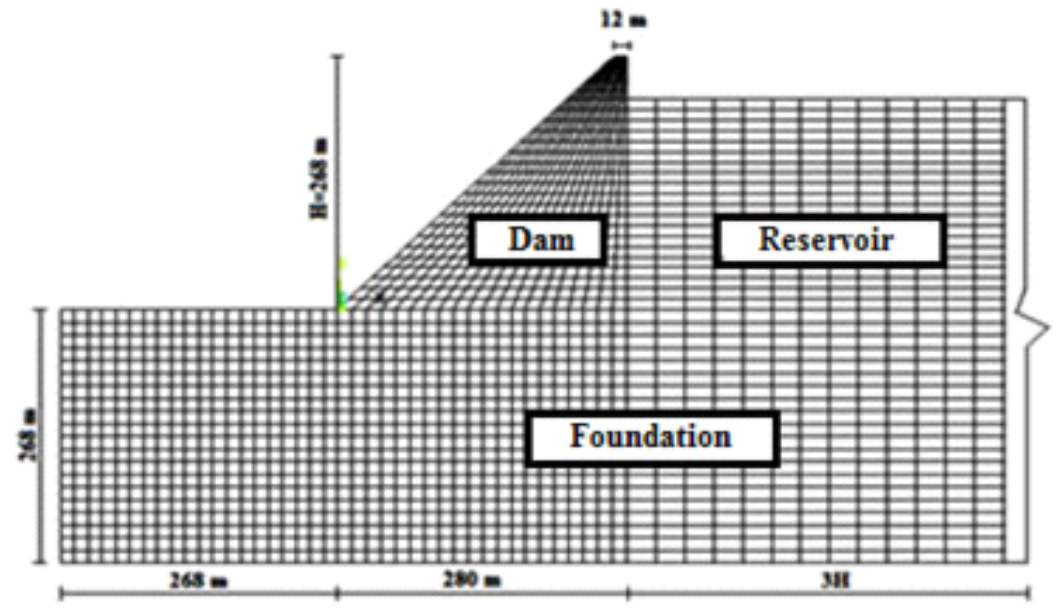

Figure 1. Geometry and finite element model of dam- reservoir- foundation system

For analysis and examination of seismic uncertainty of the Watana dam, the horizontal and vertical components of the accelerograph of San Fernando earthquake has been applied. This earthquake occurred on 1971 in America, San Fernando region with 5 kilometers depth. The horizontal and vertical components of accelerograph recorded from the earthquake have been illustrated in Figures 2. and 3.

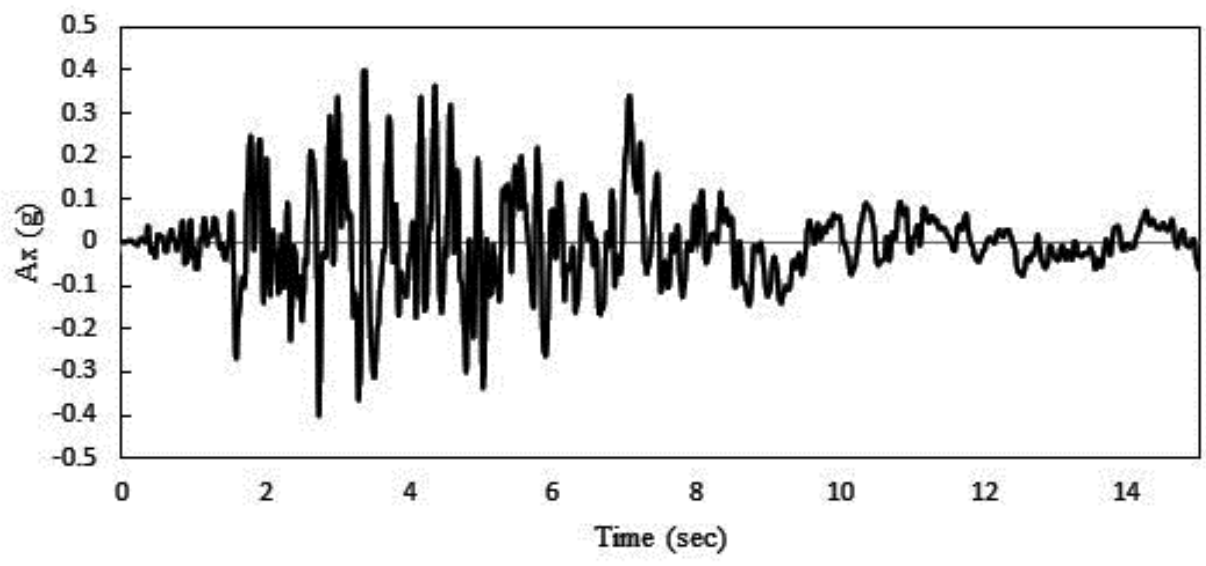

Figure 2. Horizontal component of San Fernando earthquake 


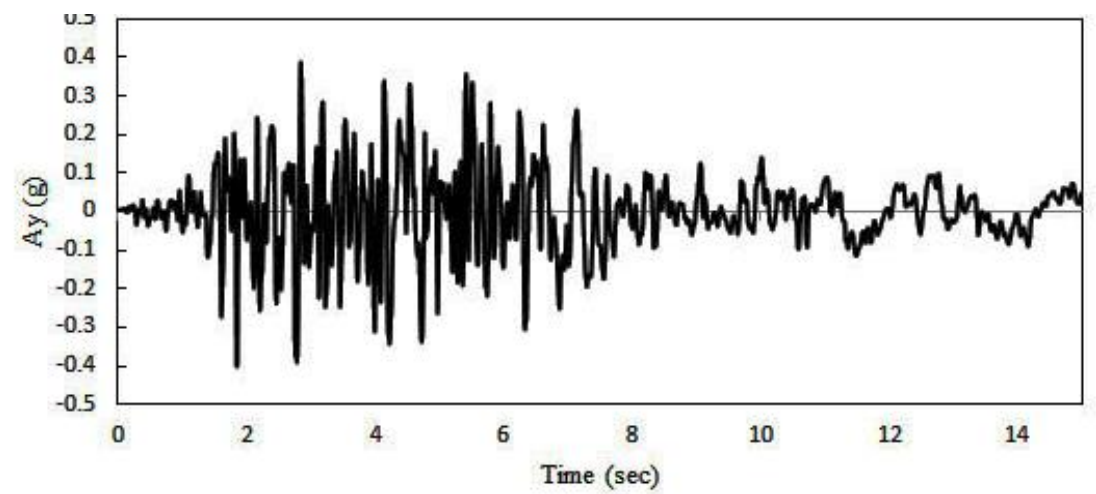

Figure 3. Vertical component of San Fernando earthquake

\subsection{Model Verification}

For evaluation of efficiency of finite element model, at firs the model was analyzed statically and the value of hydrostatic pressure at the heel of dam was comprised with analytical value. Figure 4. shows the of hydrostatic pressure contour in the reservoir obtained from software. It is obvious from contour, the value of maximum hydrostatic pressure in the hell of dam is $2.18 \mathrm{MPa}$. The analytical value is calculated according to the $P=\rho g h$ equation. In which, $P$ is the hydrostatic pressure, $\rho$ is the water density, $g$ is gravity acceleration, $h$ is the height of the reservoir. So, the amount of hydrostatic pressure at the bottom of the reservoir will be $P=1000 \times$ $9.81 \times 222=2177820 \cong 2.1778 \mathrm{MPa}$ which is almost equal with the obtained value from Ansys software $(2.18 \mathrm{MPa})$.

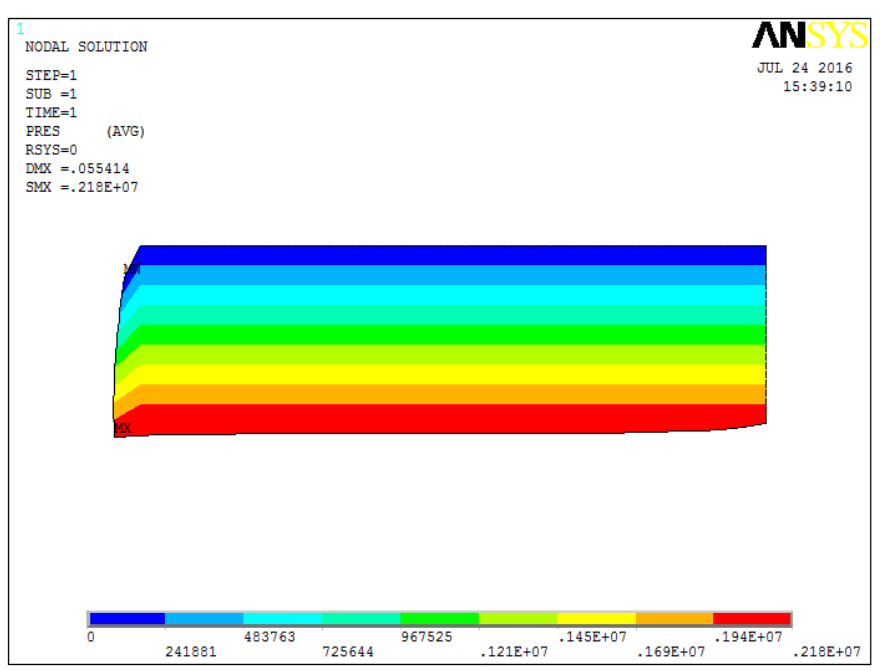

Figure 4. Contour of hydrostatic pressure distribution at the reservoir domain (Pa)

In the following, to optimize the discretization, with increasing number of division along height and width of dam body, an optimal meshing has been obtained for finite element model. The response values are displayed for different grids in Table 1. It must be mentioned that the number 7 condition has been selected for discretization of model in which the response values have been constant, approximately.

Table 1. The response values for different division of finite element model

\begin{tabular}{cccccc}
\hline Number & $\begin{array}{c}\text { Number of division } \\
\text { along height and width }\end{array}$ & $\begin{array}{c}\text { Displacement } \\
(\mathbf{c m})\end{array}$ & $\begin{array}{c}\text { Hydrodynamic } \\
\text { pressure (MPa) }\end{array}$ & $\begin{array}{c}\text { Tensile stress } \\
(\mathbf{M P a})\end{array}$ & $\begin{array}{c}\text { Compressive stress } \\
(\mathbf{M P a})\end{array}$ \\
\hline 1 & 1,2 & 12.33 & 2.16 & 2.50 & 2.16 \\
2 & 4,6 & 15.63 & 2.10 & 8.10 & 4.79 \\
3 & 10,15 & 16.55 & 2.06 & 13.31 & 6.59 \\
4 & 13,20 & 16.71 & 2.04 & 15.23 & 7.15 \\
5 & 16,25 & 16.81 & 2.02 & 16.89 & 7.61 \\
6 & 20,30 & 16.87 & 2.01 & 18.65 & 8.12 \\
7 & 22,34 & 16.91 & 2.00 & 19.01 & 8.35 \\
\hline
\end{tabular}

In this study, in order to investigate the uncertainty due to the effect of bedrock stiffness, $W$ parameter has been considered as input variable parameter defined as the ratio of bedrock to dam body stiffness. In Monte Carlo method, uniform probabilistic distribution has been assumed as probabilistic function. According to the mentioned conditions, 
all the basic and important parameters in designing of system have been considered as output parameters and the results related to probabilistic analysis and uncertainty of structure have been presented.

\section{Results}

After analysing the model, the effect of bed rock to dam body stiffness $(W)$ is shown toward the important design criteria such as hydrodynamic pressure at the bottom of reservoir, dam crest displacement and principle stresses. Then induced tensile stress at the critical parts of dam is evaluated and comprised with allowable value. In Figures 5. and 6, the variation of hydrodynamic pressure at the heel and dam crest displacement against the $W$ parameter has been depicted, respectively.

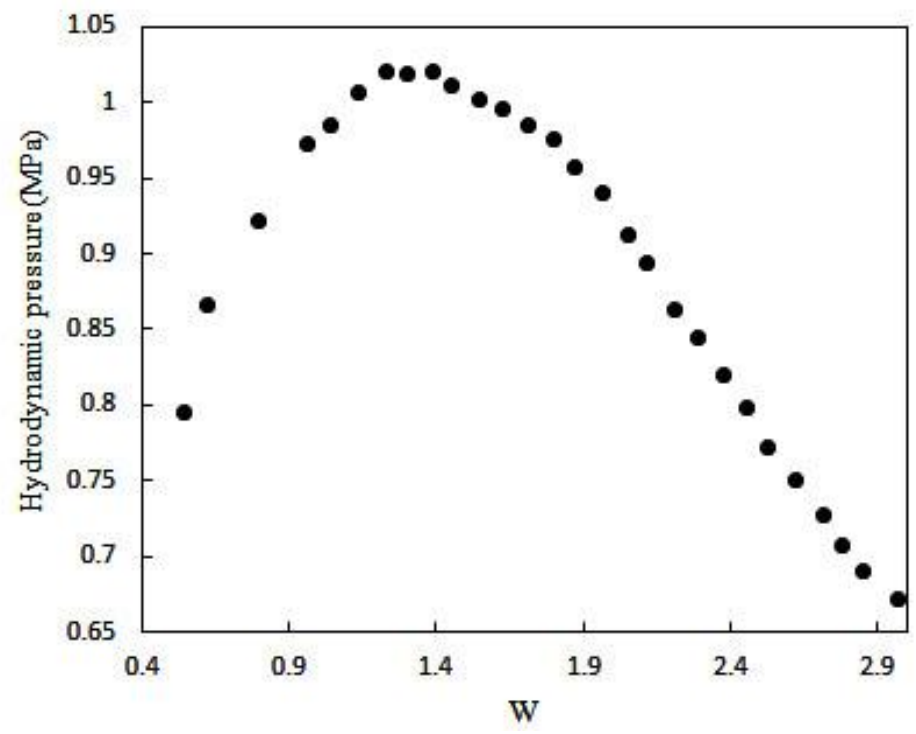

Figure 5. Sensitivity of hydrodynamic pressure at the heel of dam to $W$ coefficient

It is obvious from Figure 5, in high and low value of $W$ the hydrodynamic pressure has low value while in the ratio of 1.38 hydrodynamic pressure has maximum value. In fact, at first by increasing of $W$ coefficient, the hydrodynamic pressure is increased to reach a maximum value. Then, by increasing of $W$ hydrodynamic pressure is decreased.

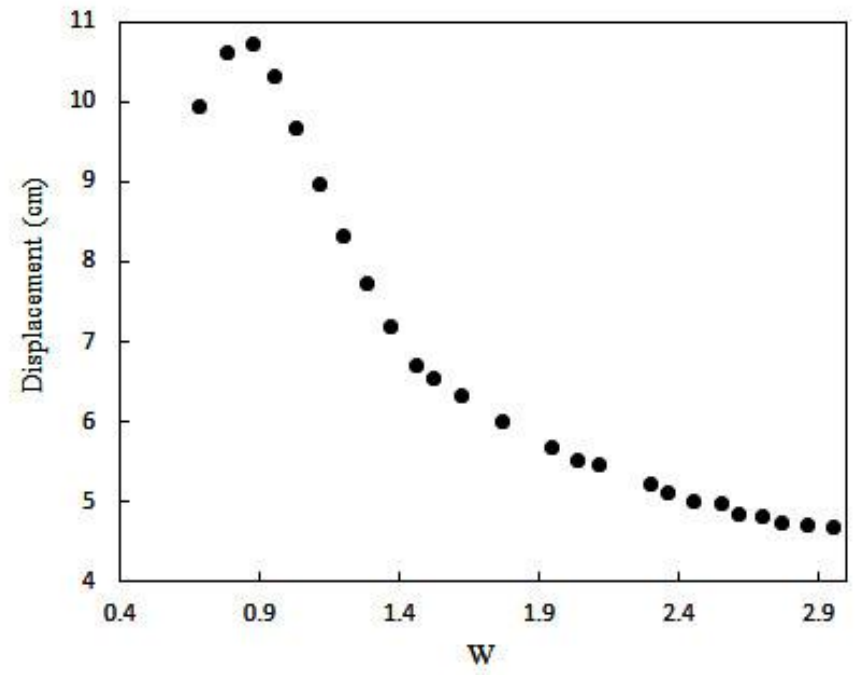

Figure 6. Sensitivity of dam crest displacement to $W$ coefficient

Figure 6. illustrate that, in ratio of 0.88 of $W$ coefficient, the dam crest displacement is maximum. After this value, with increasing of $W$ the displacement is reduces, significantly. From 2.6 ratio to more, foundation has rigid behaviour and further increase has no effect on responses.

In the following, tensile stress at the heel and compressive stress at the toe of dam have been shown in Figures 7 . and 8 , respectively. 


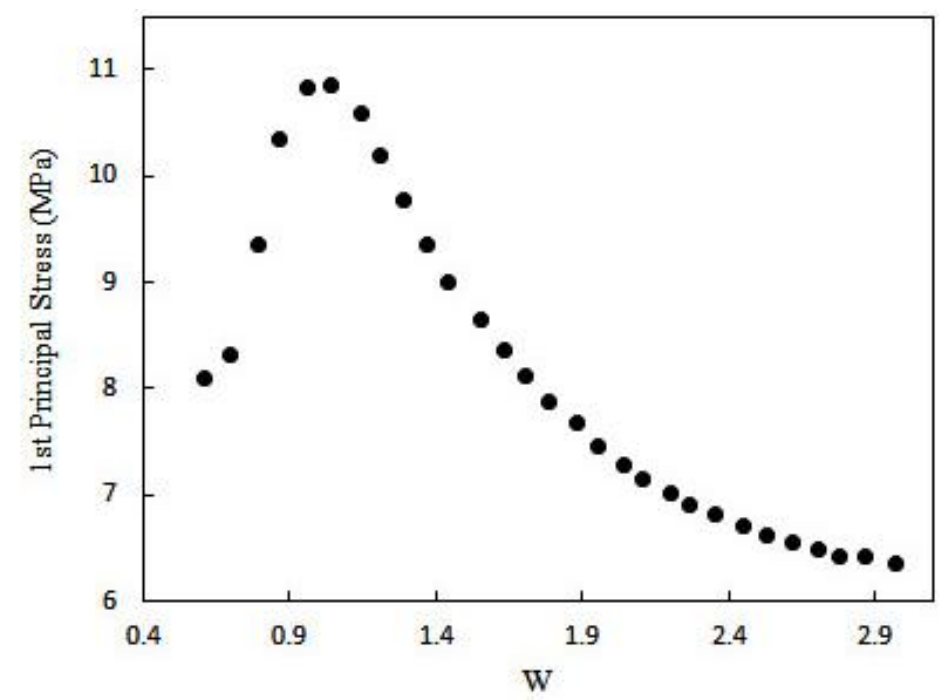

Figure 7. Sensitivity of tensile stress at the heel of dam to $W$ coefficient

According to the Figure 7, it is worth to mention that the $W$ parameter severely plays an effective and determinant role in variation of tensile stress. The sensitivity curve of tensile stress has a maximum point for specified value of $W$ which shows the critical state.

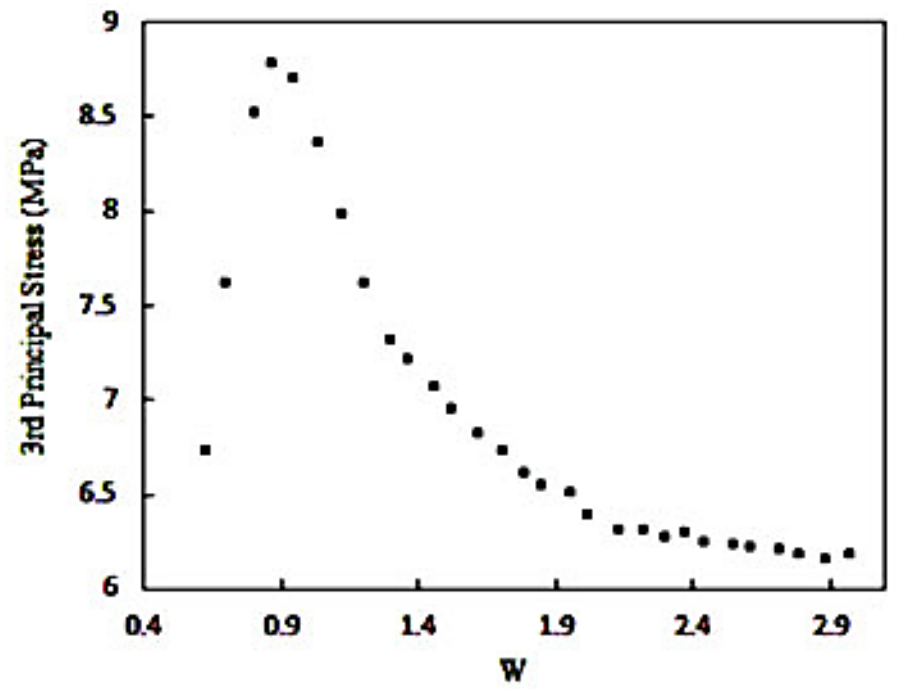

Figure 8. Sensitivity of compressive stress at the toe of dam to $W$ coefficient

Figure 8. shows that critical value of $W$ is equale to 0.87 for maximum value of compressive stress. Increase in $W$ coefficient makes foundation to be rigid and leads to constancy of compressive stress.

To better evaluation of the obtained results from sensitivity diagrams, the results have been depicted numerically in Table 2. considering the critical value of ratio of bedrock to dam body stiffness $\left(W_{C r}\right)$ in which the responses have maximum value.

Table 2. Summary of the uncertainty analysis results due to the effect of ratio of bedrock to dam body stiffness

\begin{tabular}{ccc}
\hline Responses & $\boldsymbol{W}_{\boldsymbol{C r}}$ & Maximum responses \\
\hline $\begin{array}{c}\text { Hydrodynamic pressure of reservoir } \\
\text { bottom }\end{array}$ & 1.38 & $1.01(\mathrm{MPa})$ \\
Dam crest displacement & 0.87 & $10.72(\mathrm{~cm})$ \\
Tensile stress of dam heel & 1.03 & $10.84(\mathrm{MPa})$ \\
Compressive stress of dam toe & 0.87 & $8.78(\mathrm{MPa})$ \\
\hline
\end{tabular}

In this section, Cumulative Distribution Functions (CDF) of the output parameters are illustrated. CDF is alternatively referred to in the literature as cumulative probability function. Cumulative distribution function, expresses probability by which the random variable assumes a value less than or equal to some value. Figures 9 . to 12 . show the cumulative distribution function of the selected responses of the model. 


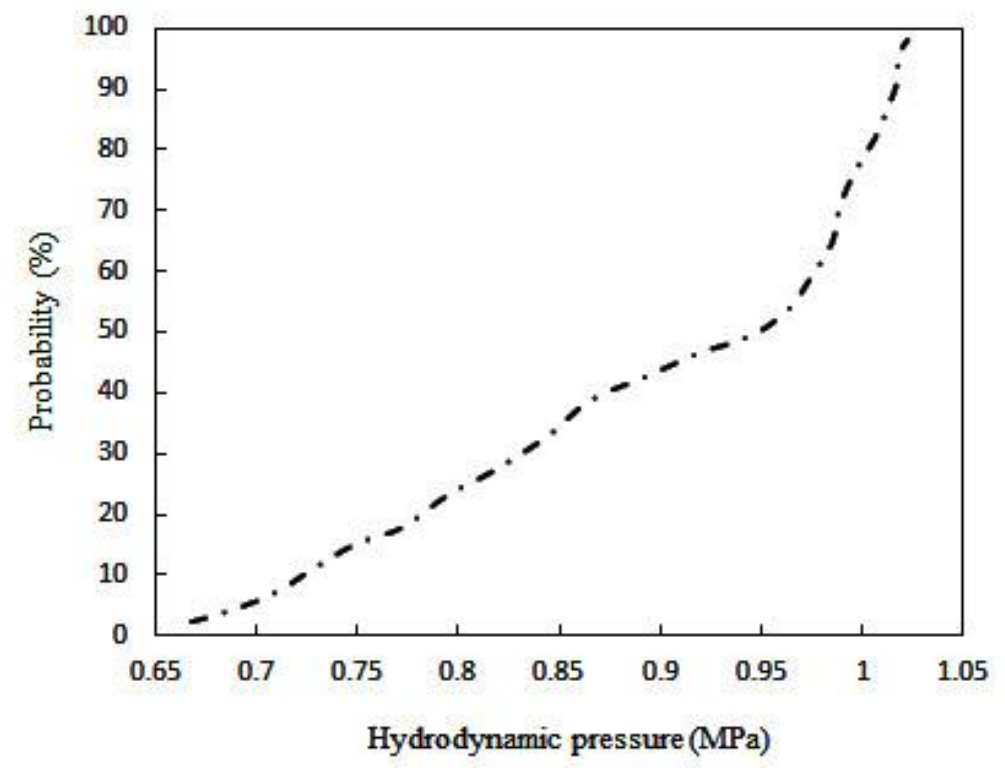

Figure 9. Cumulative distribution function of maximum displacement of dam crest

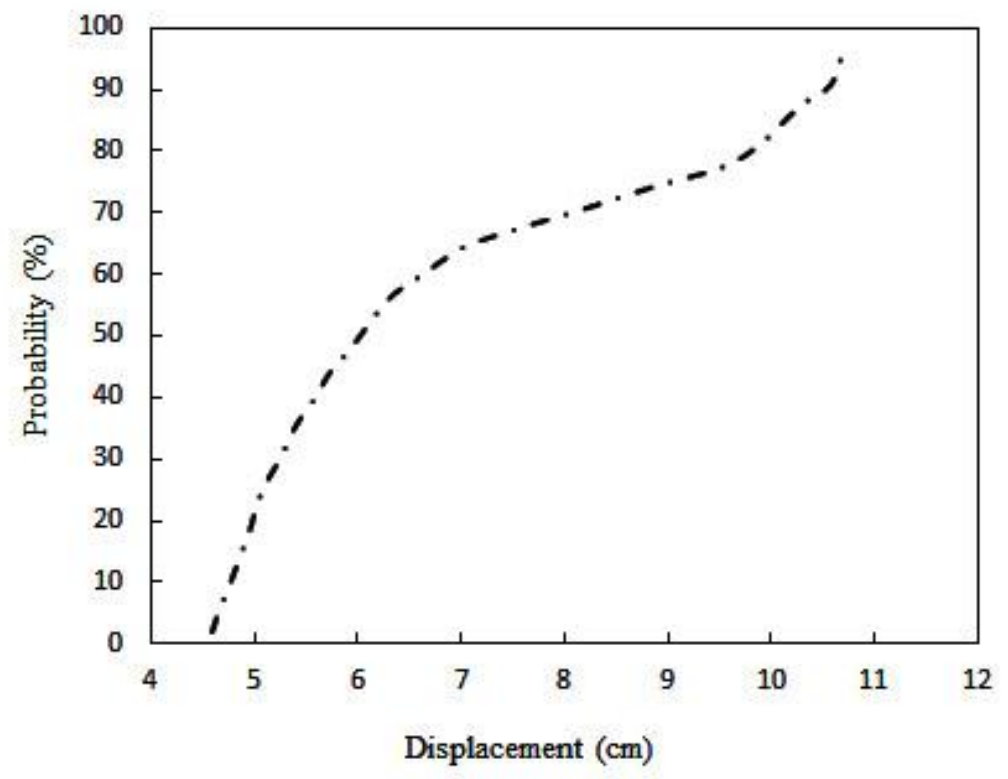

Figure 10. Cumulative distribution function of maximum hydrodynamic pressure

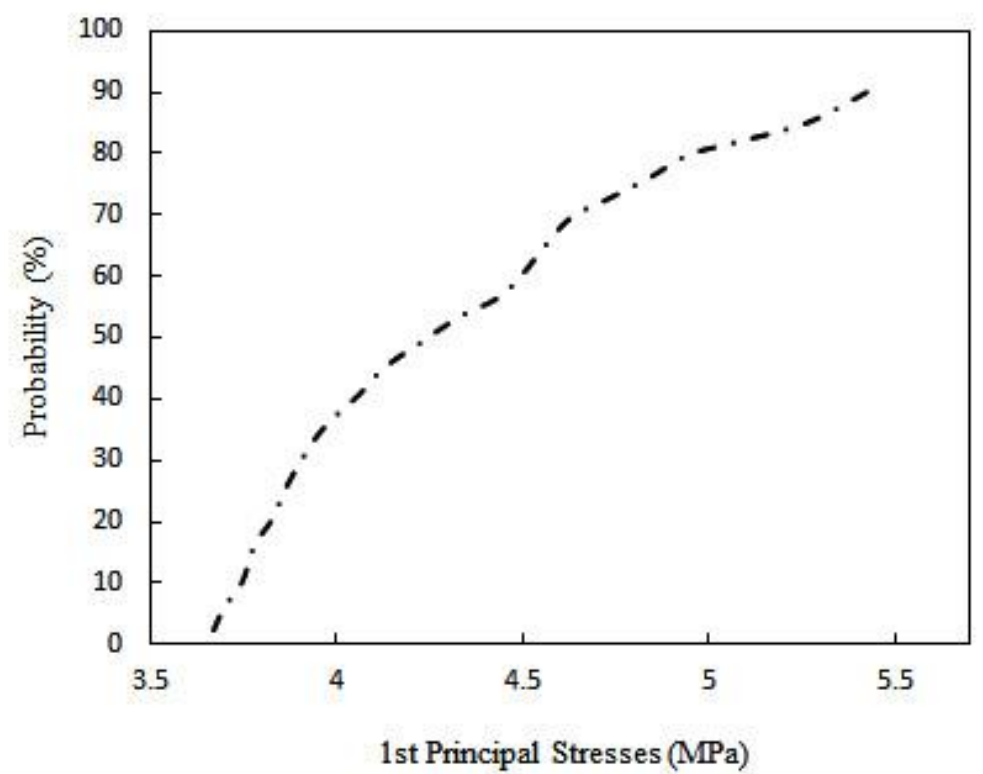

Figure 11. Cumulative distribution function of maximum tensile stress at the heel of dam 


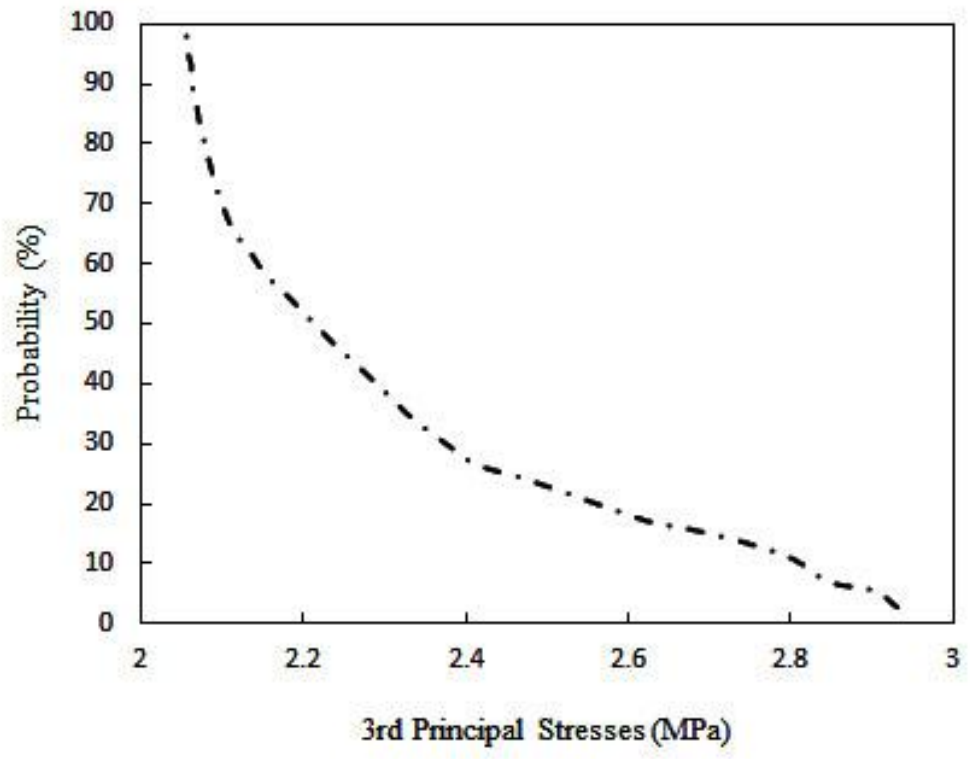

Figure 12. Cumulative distribution function of maximum compressive stress at the toe of dam

For example, according to the above diagrams it can say that:

- There is about $50 \%$ probability that the hydrodynamic pressure at the bed of dam-reservoir interface remains below $0.94 \mathrm{MPa}$.

- There is about $100 \%$ probability that the dam crest displacement to be above $4.50 \mathrm{~cm}$.

- The probability that the tensile stress exceeds $4.25 \mathrm{MPa}$ is about $50 \%$.

- There is about $50 \%$ probability that the 3rd principle stress at the toe of dam remains about 2.20 MPa.

In the following, the maximum induced compressive stress at the body of dam will be investigated to compare the allowable value. In equation 7 , the relation between modulus of elasticity of dam concrete and allowable compressive strength has been presented [23]:

$$
E=4700 \sqrt{\mathrm{f}_{\mathrm{c}}}
$$

In which $E$ is modulus of elasticity of concrete and $f_{c}$ is compressive strength of concrete with $M P a$ unit.

Consider to equation 7 , if the modulus of elasticity of concrete is assumed $25000 \mathrm{MPa}$, the allowable compressive stress will be equal to $\hat{f}_{c}=28.80 \mathrm{MPa}$. It is observed from results, the allowable compressive stress has a high difference with the maximum compressive stresses induced at the critical parts of dam body. So, it can be concluded that compressive stress in dam body is controllable. Therefore, according to the discussion, induced tensile stress in dam body because of interaction effect is investigated in the following.

\section{Concrete allowable tensile stress}

By increasing the compressive strength of concrete, tensile strength of concrete will increase with a slower speed. The researches have shown that the ratio of concrete tensile strength to its compressive strength is 10 to 11 percent for concrete with low strength, 8 to 9 percent for concrete with moderate strength and about 7 percent for concrete with high strength. Some of the researchers have suggested the following relation for determining the average tensile strength $\left(f_{\text {ctm }}\right)$ obtained from Brazilian test [24]:

$$
\mathrm{f}_{\mathrm{ctm}}=0.54 \sqrt{\hat{\mathrm{f}}_{\mathrm{c}}}
$$

In which $\hat{f}_{c}$ is compressive strength of concrete with $M P a$ unit.

European Standard CEB-FIP presents the relation below for determination of average tensile strength of splitting test:

$$
\mathrm{f}_{\mathrm{ctm}}=0.3\left(\mathrm{f}_{\mathrm{c}}\right)^{2 / 3}
$$

Concrete tensile strength due to bending or rupture modulus $f_{r}$ is obtained 50 to 100 percent greater than the concrete tensile strength in direct tension.

ACI318 code has suggested the following relation to determine the rupture modulus: 


$$
f_{r}=0.7 \sqrt{f_{c}}
$$

To determine concrete tensile strength, Raphael conducted 12000 models of tests. Finally, after arrangement of diagrams and the results of lab tests, he presented the following relation for concrete tensile strength in dynamic mode [25]:

$$
\sigma_{t}=2.6 \hat{f}_{c}^{2 / 3}
$$

In which $\sigma_{t}$ and $f_{c}$ are tensile strength and compressive stress of concrete, respectively and their unit is Psi.

In this study, the strength of concrete is assumed constant and in every stage of analysis, the allowable strength is fixed. Also, equation 11 has been used to determine the allowable strength. Therefore, the allowable tensile strength equals to

$$
\sigma_{t}=0.495(28.80)^{2 / 3}=4.65 \mathrm{MPa}
$$

In the following, the critical and highlighted points have been displayed in Figure 13. and then the diagrams of different paths of tensile stress are shown in Figures 14 to 16.

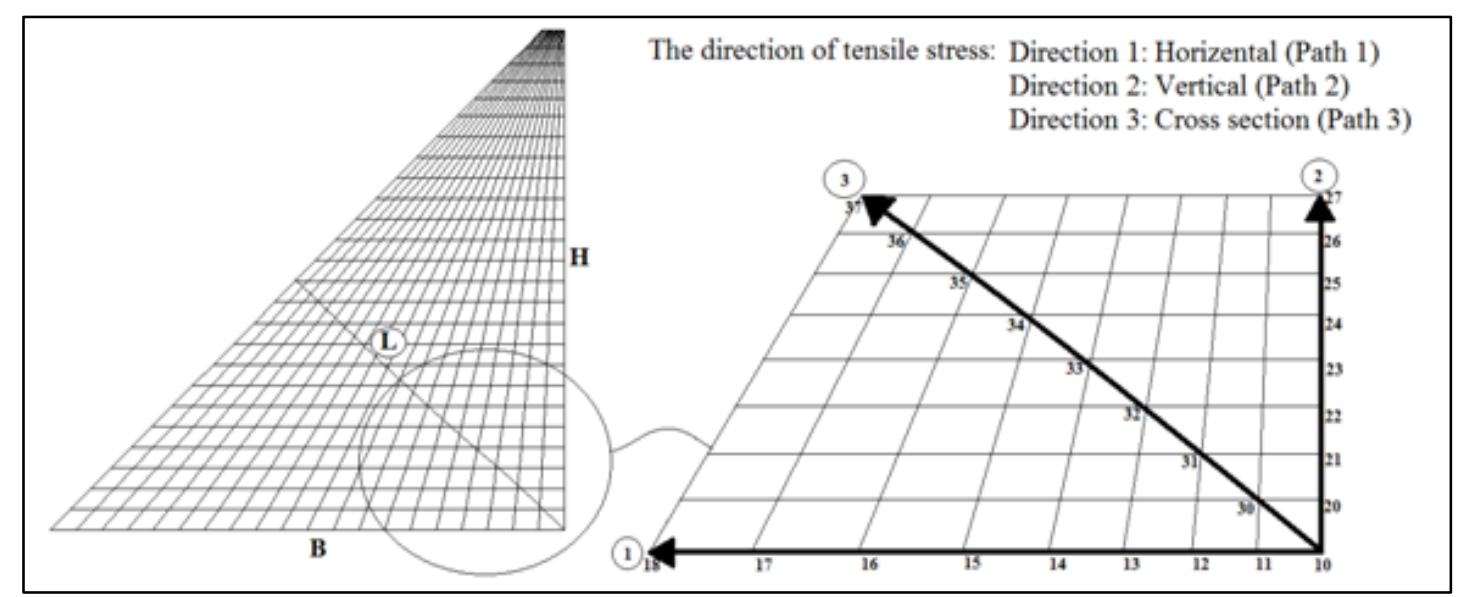

Figure 13. Selected paths for evaluation of principle tensile stress around dam heel

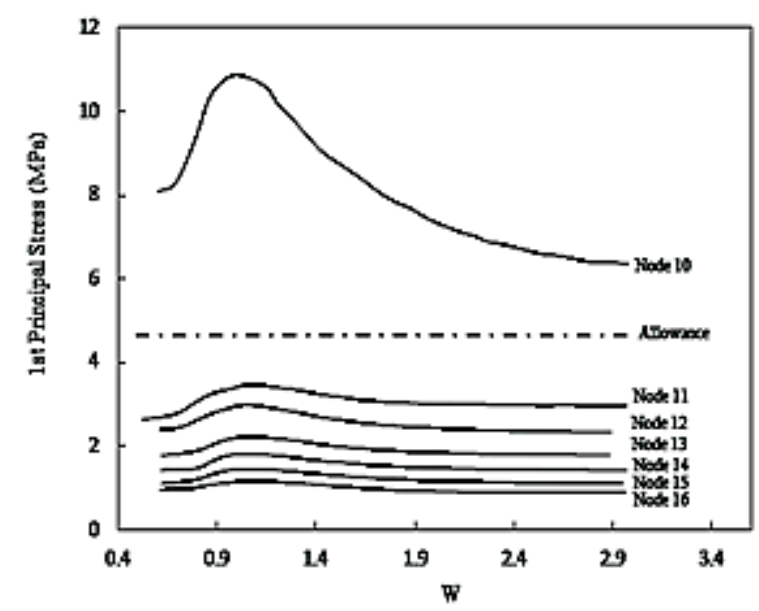

Figure 14. Sensitivity of tensile stress formed in path 1 and comparison with allowable value

With respect to the diagram in path 1 which has been selected horizontally, all points do not exceed the allowable tensile stress except the heel point and in this way the tensile stress had been controlled approximately. Moreover, regarding to the tensile stress diagram in different nodes, there is one maximum point of $W$ coefficient that is 1.15 in this path. Also, according to the diagram, it can be found that from one range, the increasing of bedrock stiffness do not have any effect on the stresses and it can be concluded that foundation has a rigid behavior and the beginning of this behavior can be considered as an appropriate point concerning the ratio of bedrock stiffness to the stiffness of body dam. 


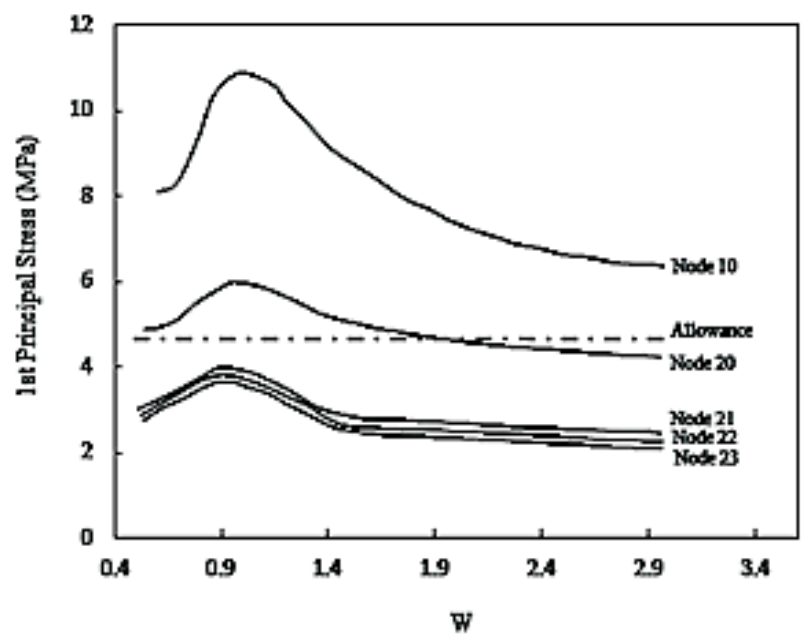

Figure 15. Sensitivity of tensile stresses shaped on path 2 and comparison with allowable value

Figure 15. shows that, along the height (path 2), in two nodes the tensile stress in dam body exceeds the allowable tensile stress. Actually, in height of 0.05 from total height of dam, there are tensile cracks on the body of dam. So, proper ratio can be chosen for control of tensile stress in this way and in whole structure. The most suitable ratio is 2.40 according to economic and safety point of view.

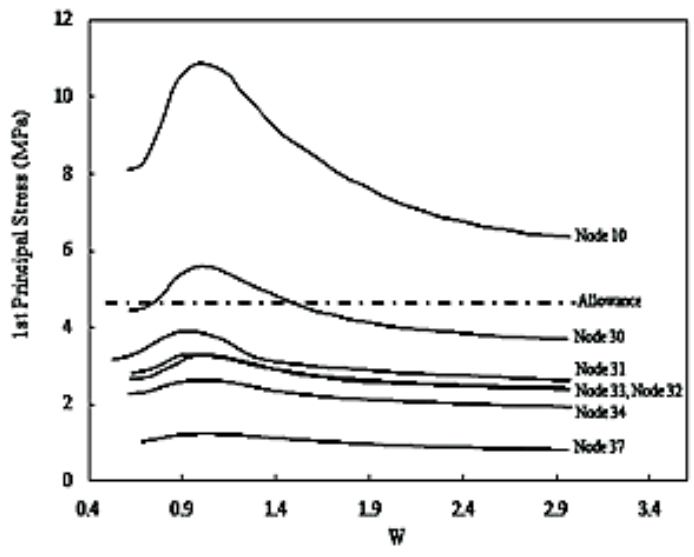

Figure 16. Sensitivity of tensile stresses formed in path 3 and comparison with allowable value

Figure 16. illustrate that in path 3 of the tensile stress shaped in dam, it is visible that allowable stress has been controlled completely up to node number 31 . Regarding that the length of horizontal, vertical and cross paths are 280 , 268 and 198 meters respectively, a $d_{C}$ parameter has been defined which shows the depth of tension crack in mentioned directions and the value of tensile stress in the end of $d_{C}$ has been obtained for critical $W$. Table 3. illustrates the summary of numerical values of results.

Table 3. Summary of the results for tensile cracks probability due to the effect of $W$

\begin{tabular}{cccc}
\hline Path of tensile stress & $\boldsymbol{W}_{\boldsymbol{C} \boldsymbol{r}}$ & $\boldsymbol{d}_{\boldsymbol{C}}(\boldsymbol{m})$ & Value of tensile stress (MPa) \\
\hline 1 & 1.12 & $0.02 \mathrm{~B}$ & 3.46 \\
2 & 0.95 & $0.04 \mathrm{H}$ & 6.00 \\
3 & 1.03 & $0.06 \mathrm{~L}$ & 5.60 \\
\hline
\end{tabular}

In Table 3, $W_{C r}$ represents the critical value of $W$ in which the induced tensile stress in dam body has maximum value. In the following, according to the selected path, the trend of tensile stress distribution has been shown in three directions and in the most critical ratio of $W$ has been shown in Figures 17. to 19. in which B is the bed width, $\mathrm{H}$ is the height of dam and $\mathrm{L}$ is the length of crack extend in path 3 . 


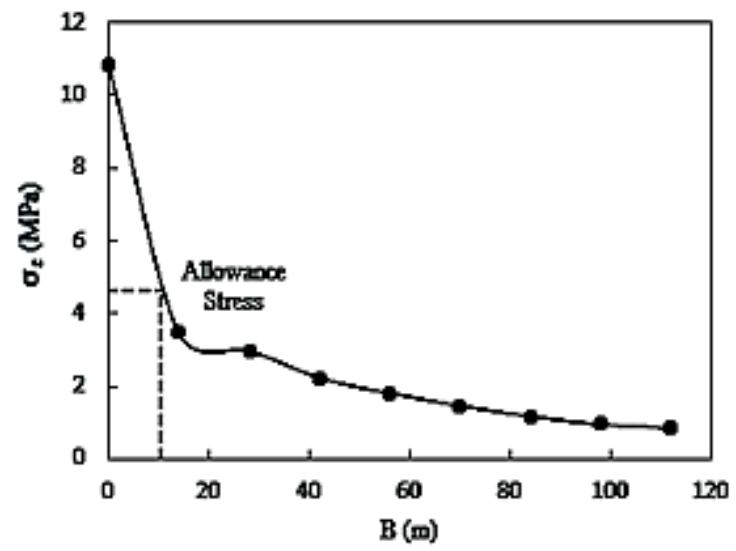

Figure 17. Trend of tensile stress distribution along the horizontal path

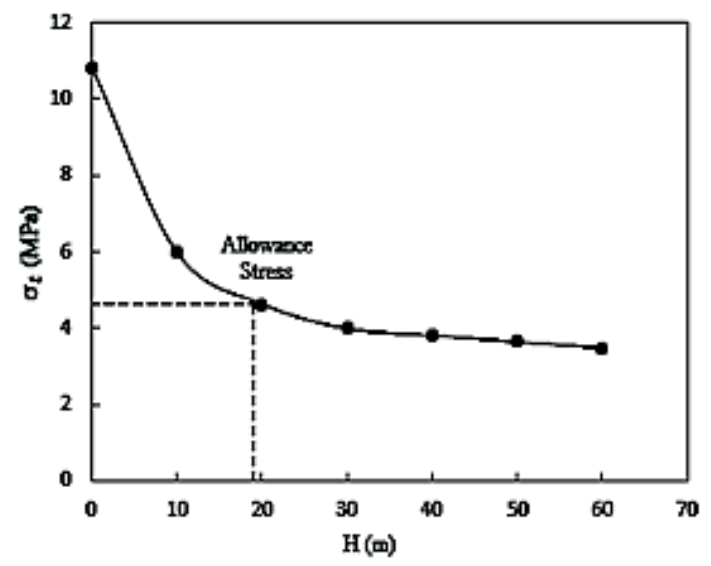

Figure 18. Trend of tensile stress distribution along the vertical path

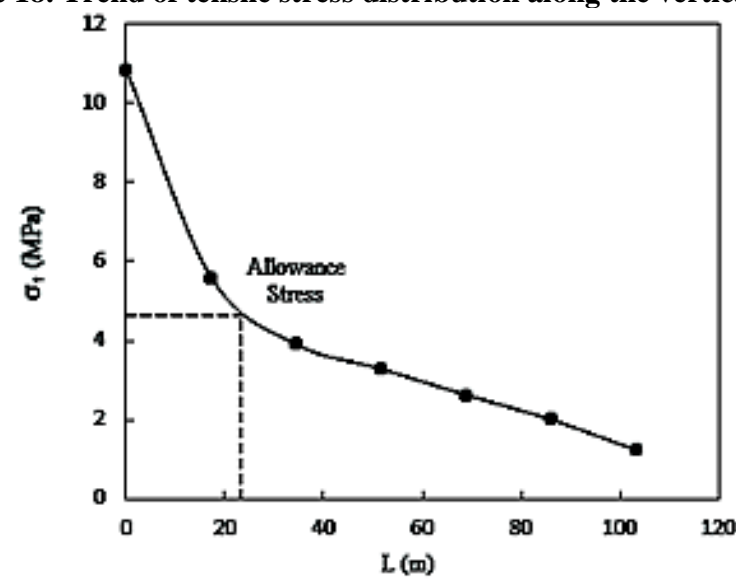

Figure 19. Trend of tensile stress distribution along the cross path (direction 3)

According to the Figures 17. to 19, the advancement of crack in the mentioned paths can be found out. As the curves manifest, at the bed of dam the tensile stress exceeds the allowable value up to 20 meter length of heel. This value is 30 meters at the height and 40 meters at the cross path which show that the progress of tensile cracks at the cross path has a more critical condition during the earthquake and it needs to control and restoration.

\section{Conclusion}

In this research, the uncertainty analysis is presented to show the effect of bedrock and dam body stiffness ratio $(W)$ on seismic performance of RCC dam. For this purpose, the Monte Carlo simulation with Latin Hypercube sampling is used for probabilistic analysis of dam-foundation-reservoir system. The Watana dam was considered as case study to illustrate the effect of $W$ on the selected output parameters. The model was investigated by exertion of dynamic interaction of dam, reservoir and foundation considering linear behavior for concrete and with applying of San Fernando earthquake. For investigation of the effect of $W$ on output parameters, the results were obtained as sensitivity curves and cumulative distribution functions. In order to examine and select the most proper ratio of $W$ coefficient, the output responses effective in design were evaluated. In the concrete dam, the compressive stress criterion was controlled 
completely and the parameter of tensile stress at dam body was investigated as a critical factor in seismic design. So, in this paper the probability of creation of tensile cracks was investigated in the form of stress paths assuming three directions. Consider to results, it is possible to recognize the parts of dam body which is probable for tensile cracks. Also, consider to curves, one can select the optimum value of $W$ in which the induced stresses are less for economic design. For example, by considering all responses and control of tensile stress at the heel of dam with allowable stress, the values more than 2.30 for coefficient $(W)$ were chosen as the suitable value for the selected case in this research. On the basis of this ratio, if the location of dam construction is not determined, geotechnical tests can contribute to determine the most secure place for construction of dam.

\section{References}

[1] Chuhan, Z. Guanglun, Shaomin, W. Yuexing, D. "Experimental tests of rolled compacted concrete and nonlinear fracture analysis of rolled compacted concrete dams." Journal of materials in civil engineering (2002): 108-115.

[2] Hui, Z., Trevor, H. "Regularization and variable selection via the elastic net." Stanford University, USA. J. R. Statist 67. No. 2 (2004): 301-320.

[3] Ghobarah, A. "Performance-based design in earthquake engineering: state of development." Engineering structures 23(2001): 878-884.

[4] Dolsek, M. "Incremental dynamic analysis with consideration of modelling uncertainties." Earthquake engineering and structural dynamics 38(2009): 805-825.

[5] Hwang, H. H. M., Jaw, J. W. "Probabilistic damage analysis of structures." ASCE Journal of structural engineering 116(1990): 1992-2007.

[6] USACE, Gravity dam design. United States army corps of engineers, engineering manual, 1995.

[7] Rubinstein, R. Y. Simulation and the Monte Carlo method. John Wiley and Sons, New York, 1981.

[8] Luco, N., Cornell, C. A. "Effects of connection fractures on SMRF seismic drift demands." ASCE Journal of structural engineering 126(2000): 127-136.

[9] Porter, K. A., Beck, J. L., Shaikhutdinov, R. V. "Sensitivity of building loss estimates to major uncertain variables." Earthquake Spectra 18(2002): 719-743.

[10] Leclerc, M., Leger, P., Tinawi, R., CADAM user's manual. Department of civil, geological and mining engineering. Ecole Polytechnique de Montreal, Quebec, 2001.

[11] Altarejos-Garcia, L., Escuder-Bueno, I., Serrano-Lombillo, A. Estimation of the probability of failure of a gravity dam for the sliding failure mode: 11th ICOLD Benchmark workshop on numerical analysis of dams, Theme C, Valencia, 2011.

[12] Carvajal, C., Peyras, L., Bacconnet, J., Becue, P. "Probability modeling of shear strength parameters of RCC gravity dams for reliability analysis of structural safety." European Journal of environmental and civil engineering 13(2009): 91-119.

[13] Alembagheri, M., Seyedkazemi, M. "Tensile strength of concrete." Earthquake engineering and structural dynamics earthquake (2014): 41-58.

[14] Pasbani Khiavi, M. "Investigation of the effect of reservoir bottom absorption on seismic performance of concrete gravity dams using sensitivity analysis." KSCE Journal of civil engineering, Korean society of civil engineers 20. No. 5 (2015): 1977-1986.

[15] Lupoi, A., Callari, C. "A Probabilistic Method for the Seismic Assessment of Existing Concrete Gravity Dams." Structures and Infrastructure Engineering 8(2012): 985-989.

[16] Ghanaat, Y., Patev, R., Chudgar, A. "Seismic Fragility Analysis of Concrete Gravity Dams." In: Proceedings of the 15th World Conference on Earthquake Engineering, Lisbon, Portugal, (2012).

[17] Ghanaat, Y., Patev, R., Chudgar, A. "Seismic Fragility for Risk Assessment of Concrete Gravity Dams." In: Proceeding of the USSD Annual Conference (2015): 645-60.

[18] Pasbani M. "Investigation of seismic performance of concrete gravity dams using probabilistic analysis." GRAĐEVINAR 69. No. 1. (2017):21-29.

[19] Aliberti D., Ernesto Cascone E. and Biondi G. "Seismic performance of the San Pietro dam." Procedia Engineering 158(2016): $362-367$.

[20] Ansari M.I., Pankaj Agarwal P., "Effects of re-entrant corner on seismic performance of high concrete gravity dams" Procedia Engineering 173(2017): 1886 - 1893

[21] Zienkiewicz, O. C., Bettess, P. "Dynamic fluid-structure interaction: Numerical modeling of the coupled problem." John wiley, New york (1978): 185-193.

[22] Ansys user manual. Release 11.0 Documentation for ANSYS.” SASIP, Inc, 2007. 
[23] ACI 318-05, Building code requirements for structural concrete and Commentary-ACI 318R-05. American concrete institute, Farming Hills, MI, USA, 2005.

[24] Silva, B. V., Barbosa, M. P., Silva Filho, L. C. P., Lorrain, M. S. "Experimental investigation on the use of steel-concrete bond tests for estimating axial compressive strength of concrete." IBRACON Structures and material journal (2013): 715-736.

[25] Raphael, J. M. "Tensile strength of concrete." ACI 81. No. 2 (1984): 158-165. 